\title{
Correction to: Surgical Morbidity in the Elderly Bariatric Patient: Does Age Matter?
}

\author{
Andrés Esteban San Martin ${ }^{1} \cdot$ Matías Sepúlveda $^{1,2} \cdot$ Felipe Guzmán $^{3} \cdot$ Hernán Guzmán ${ }^{2}$ - Felipe Patiño ${ }^{2}$. \\ Yudith Preiss ${ }^{2}$
}

Published online: 7 June 2019

(C) Springer Science+Business Media, LLC, part of Springer Nature 2019

\section{Correction to: Obesity Surgery \\ https://doi.org/10.1007/s11695-019-03876-7}

Due to a metadata tagging error the name of author Andrés Esteban San Martín was indexed incorrectly. The author's given name is Andrés Esteban and his family name is San Martín.

Publisher's Note Springer Nature remains neutral with regard to jurisdictional claims in published maps and institutional affiliations.

The online version of the original article can be found at https:/doi.org/ 10.1007/s11695-019-03876-7

Matías Sepúlveda

drmsepulveda@gmail.com

Andrés Esteban San Martin

andresesanmartin@gmail.com

Felipe Guzmán

felipe.igm26@gmail.com

Hernán Guzmán

hernus87@gmail.com

Felipe Patiño

felipepatino@gmail.com
Yudith Preiss

yudith.preiss@gmil.com

Escuela de Medicina, Universidad Diego Portales, Av. Ejército Libertador, 141 Santiago, Chile

2 Bariatric and Metabolic Surgery Center, DIPRECA Hospital, Vital Apoquindo 1200, Las Condes, Santiago, Chile

Escuela de Medicina, Universidad de Santiago, Av Libertador Bernardo O’Higgins, 3363 Santiago, Chile 